\title{
CIB2007-486
}

\section{Feng Shui: An Alternative Framework for Complexity in Design}

\author{
Michael Y. MAK and S. Thomas NG
}

\begin{abstract}
The nature of the building design is a very complex process that requires an integration of creativity, rationality and self-organization. Although there are numerous studies on examining how architects learn and apply their knowledge to design new buildings, the design process still cannot be explicitly defined. As the way architectural design knowledge is applied to building design cannot be formulated, the term "black box" is used to represent an architect's design mechanism that cannot be logically explained. Designers bring intuition and individual past experiences to make heuristic decision to tackle new situation of building design. These characteristics are similar to the Chinese philosophy of direct insight into the nature and the principles and practice of Feng Shui as applied to building design. Feng Shui is traditional Chinese wisdom which aimed at creating a harmony among environment, buildings and people. This paper investigates an alternative framework for building design derived from the principles and practice of Feng Shui.
\end{abstract}

\section{Keywords}

Feng Shui, Building Design, Complexity in Design

\section{INTRODUCTION}

The nature of design falls between science and art, and architectural design is a complex and intuitive process. Architects used their knowledge from past experiences, and from their own theories to create spaces with desired experiential qualities (Suckle, 1980). Jones (1970) recognized the complexity of design process and suggested that a designer working on a problem is engaged simultaneously in three types of activity: 
(1) Creativity: a designer is a black box out of which comes a mysterious creative leap,

(2) Rationality: a designer is a glass box inside which can be discerned a completely explicable rational process, and

(3) Control over the design process: a designer is a self-organising system capable of finding short cuts across unknown territory.

This integrative design process is similar to the Chinese holistic view and the Feng Shui approach to the built environment.

Feng Shui is a body of ancient Chinese wisdom in knowledge and experience related to the built environment that has been accumulated for more than three thousand years. It is founded from the earliest and greatest philosophy document of Chinese, Yi Jing (The Book of Changes) that developed ca. 800 B.C. The primitive knowledge of Feng Shui was based on the observation from three sources: astronomical phenomena, natural phenomena and human behaviour (Feuchtwang, 1974).

There are two main schools of thought and practice in Feng Shui: the Compass School and the Form School. The Form School approach has been well recognized and widely accepted by Feng Shui researchers as comprising the scientific bases in the analysis of built environment (He, 1990; Cheng and Kong, 1993). The principles and practices of Feng Shui aimed at creating a harmonised built environment for people to live in, and it represents a traditional Chinese architectural theory for selecting favourable sites as well as a theory for designing cities and buildings (Lee, 1986).

Nowadays, as many researchers seek to establish a deeper understanding of these relationships between the human and natural environments, architects begin to recognize Feng Shui as a broad ecologically and architecturally connected paradigm. Hwangbo (1999) believed that the practice of Feng Shui is an intuitive matter involving site selection and spatial organization, and it has strong parallels with the western concept of geometry in architectural design.

This paper investigates an alternative framework for building design derived from the principles and practice of Feng Shui. Firstly, the nature and complexity of design are explored and why it is similar to the Chinese philosophy is explained. The principles and practices of Form School approach are then explained and the four fundamental concepts are derived. Finally, a conceptual framework of Feng Shui for building design is constructed based on the Form School approach. The findings of this paper contribute significantly to current practice of architectural design by creating a structured framework for building design.

\section{COMPLEXITIES IN DESIGN}


It is generally recognized that design falls somewhere between two extremes: science and art, and architectural design lies near the centre of this spectrum (Jung, 1996). Sargent (1994) studied the nature of design and suggested that there can be no unitary "science of design".

In the 1960s, design was interpreted in a similar way to the interpretation of science; the format of a scientific method was followed in the form of analysis and synthesis. This approach originated in the notions of objectivity, rationality and universalism that are believed to constitute the scientific method: breaking the problem down to fragments and solving each of these separately before attempting some grand synthesis (Asimow, 1962; Jones, 1963; Archer, 1969).

However, more researchers (Gregory, 1966; Simon, 1969) began to recognize that design is not like science. This approach was largely based on the philosophy of science developed by Popper (1972) and Kuhn (1970). Popper (1972) suggested the concept of the "ConjectureRefutation" model of the scientific method instead of the logical process of induction that laws can be inferred from true facts. Kuhn (1970) proposed a "paradigm" concept to explain the evolution of scientific knowledge where scientific knowledge progresses through "paradigm shift".

Jones (1970) admitted that it is impossible to ascertain the nature of design. He outlined three key points to describe the nature of design, which are summarized by Raftery (1991) as follows:

(a) There are very often long periods when the person who is about to make an original work seems to do nothing except take in information and labour fruitlessly at seemingly trivial aspects of a problem. This is known as "incubation".

(b) The solution to a particular problem or the occurrence of an original idea often happens when, at some particular point in time, everything seems to fall into place. This is known as the "leap of insight" or "change of set". Basically the problem is perceived in a new light and very often an apparently complex problem turns into a very much simpler one.

(c) The main enemies of originality are mental rigidity and wishful thinking.

Incubation was a concept proposed by Poincare (1929) which interpret the conditions for creativity as:

(a) A period of conscious work, data assembled, problem defined etc., and some trials made at solutions.

(b) The unconscious works at useful and fertile combinations during this time and useless areas are inhibited.

(c) A hypothesis is derived which gives a fruitful direction. In Poincare's own words as "a period of preliminary conscious work always precedes all fruitful unconscious work". 
Following the conclusions of Jones' and Poincare's work, design was described as a "problem-solving" activity. However, the solution to the problem was perceived by individual designers and not measured objectively. The further implications of both Jones and Poincare's work were that the solution is produced by an unconscious thought process. Humphreys (1976) recognized that this mystical approach is remarkably similar to the concept of "satori" (the enlightenment in Zen Buddhist thought) in Chinese philosophy.

\section{FORM SCHOOL APPROACH}

There are two main schools of thought and practice in Feng Shui: the Compass School and the Form School. The Compass School is based on metaphysical speculations of cosmology, in particular by analysing the directional aspects in terms of the relationship between the five elements, eight trigrams, heavenly stems, earthly branches and constellations. Practice in the Compass School uses primarily the Luopan (Feng Shui compass) and the composed elements of time in space (Skinner, 1982; Chiou and Krishnamurti, 1997). The Form School is primarily based on the verification of the physical configuration of mountains and watercourses surrounding sites and buildings. Its theory was built upon an understanding of the landscape: the profiles of the land, the sources of rivers and the terrain. The practice of the Form School first observes the land formation and terrain, and then determines the location and orientation of buildings.

The development of the Form School was widely accepted by the upper class of the ancient Chinese society and attracted scholars and intellectuals to join its practice. The principles of the Form School were applied to design and construct castles, palaces and towns in China since ancient times (He and Luo, 1995). Lee (1986, p.367) suggested that the principles and practices of the Form School approach represent "a compendium of Chinese architectural theory".

Since the Ming Dynasty (1368-1644), these two schools of thought were not exclusively attached to their own methods for the practice of Feng Shui, but rather combined and integrated ideas from both Compass and Form schools (Lee, 1986). However, the Form School approach remained the primary consideration in Feng Shui practice (Xu, 1990; Too, 1996). Contemporarily, Form school approach has been recognized as comprising scientific basis in the analysis of the built environment (He, 1990; Wang, 1992; Cheng and Kong, 1993; Mak and Ng, 2005). For instance, research investigations carried out by $\mathrm{Xu}(1990)$ has compared the Feng Shui concepts using the Form School approach and the Hendler model, a wellknown western model of site analysis. The results indicated that Feng Shui is a more powerful tool in site analysis than the Hendler model. 
According to Zang Shu (the Book of Burial), the first surviving important literature on Form School was written by Guo Pu (276-324), there are five main theories in terms of Form, namely Qi, Wind-water, Four Emblems, Form and Direction theories (He, 1990). The Form School approach considers mountain ridges, surrounding hills, watercourses, locations and orientations as the most important terrestrial and celestial elements for human dwellings because these elements represent both terrestrial and celestial Qi. These elements comprised the basic terms of the Form School approach and were known as the "Five Feng Shui Geographical Secrets", namely, dragon, sand, water, cave and direction (Lip, 1979):

(1) Dragon: means the mountain ridges to be traced, and represents the topography,

(2) Sand: means the enfolding hills and soil condition, and represents the surrounding environment,

(3) Water: means the flow of water through or by-passing the site,

(4) Cave: or "Feng Shui Spot" means the niche position, and represents the best location,

(5) Direction: means the facing direction of the site and building, and represents the orientation.

The five main theories of Form School approach together with these five Feng Shui Geographical Secrets are developed into four fundamental concepts of Form School approach for Feng Shui design (Mak, 2004).

\section{FOUR FUNDAMENTAL CONCEPTS OF FORM SCHOOL APPROACH}

\subsection{CONCEPT OF THE FENG SHUI MODEL}

The combination of these five Feng Shui geographical elements and the four emblems (green dragon, white tiger, black tortoise and red bird as the four cardinal directions) produced a classic Feng Shui model. This model has been interpreted in diagrams of spatial organization of auspicious mountains and watercourses in most of the ancient Feng Shui literature. Many Feng Shui researchers have summarized these diagrams into a simplified diagram of a Feng Shui model as shown in Figure 1 (Shang, 1992; Cheng and Kong, 1993; Han, 1995; Yi et al., 1996; He, 1998). This diagram illustrated the relationships between the key elements of the five Feng Shui geographical secrets being considered and how dragon vein, four emblems in sand, water feature, cave and bright court, and their directions were integrated into a Feng Shui model.

\subsection{CONCEPT OF PARALLELISM}


Most Feng Shui scholars (Skinner, 1982; Lee, 1986; Xu, 1990) recognized that the theories and practices of Feng Shui work in macrocosm and microcosm. This relationship is recognized as the concept of parallelism in Feng Shui (Lee, 1986). The concept of a Feng Shui model not only applied to landscape and site selection, but it can also be applied to the interior layout of buildings. Therefore, whether it is dealing with physical or topographical elements, or housing structure, or the proportional relationships of the interior of a house, the same principles and relationships of the Feng Shui model are still applied as shown in Figure 2.

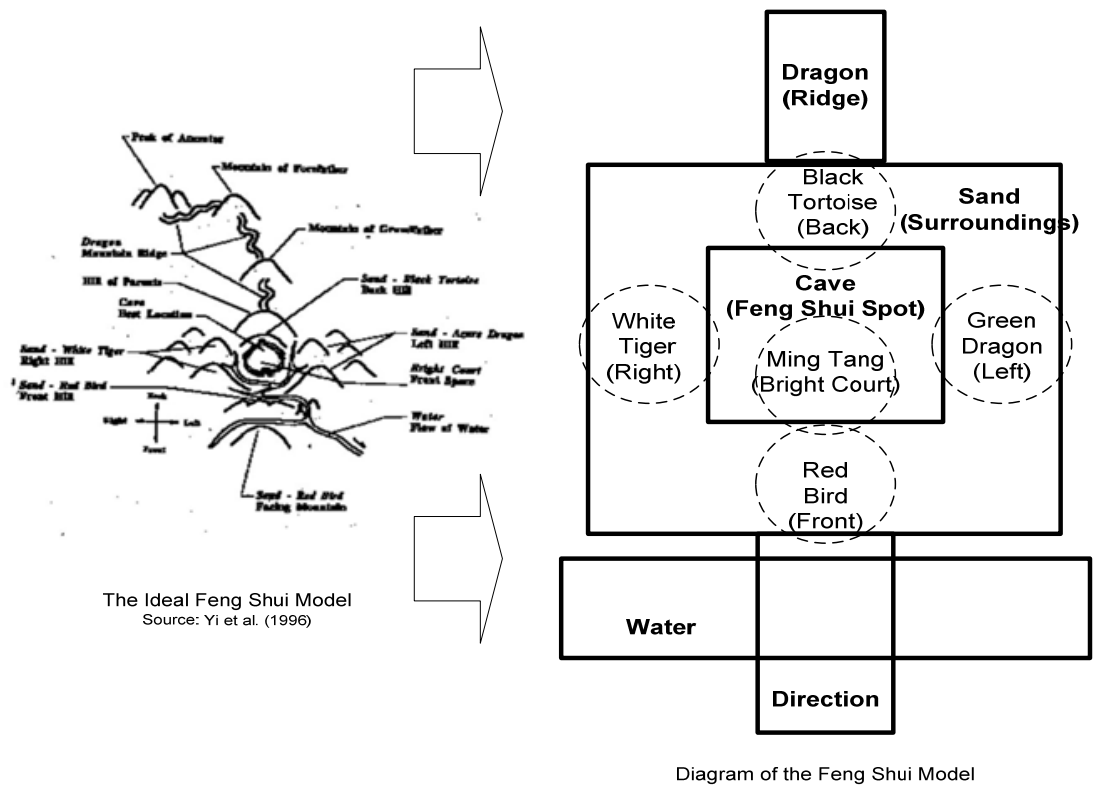

Figure 1 The Feng Shui model Source: Yi et al. (1996) and Mak (2004) 


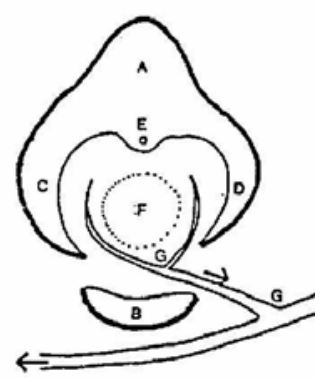

A Black Turtle

B Red Bird

C White Tiger

D Azure Dragon

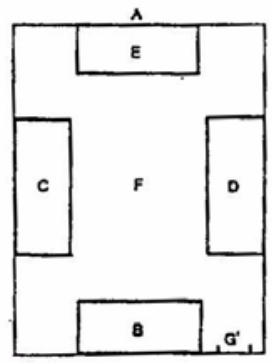

E Feng Shui Spot

F Ming Tang

G Water Mouth

G' Gate

Figure 2 Correspondence of the Four Emblems in Nature and Architecture Source: Adopted from Lee (1986)

\subsection{CONCEPT OF FOUR DESIGN MODULES}

When describing the site conditions and the design of dwellings, most of the Feng Shui texts, such as Yang Zhai Shi Shu (Ten Books on Dwellings of Living) categorized these aspects into Outer Form and Inner Form. According to Lee (1986), the Outer Form can be identified as the location of the site, conditions that surround the site, topographical conditions of the site and the shape of the site. The Inner Form can be identified as the layout of the building, elevations of the building, and elements of building. Feng Shui scholars, Cheng and Kong (1993) explained the application of the Form School approach to the design of dwellings and proposed a further classification into four design modules: surrounding environment, external layout, internal layout and interior arrangement (see Figure 3).

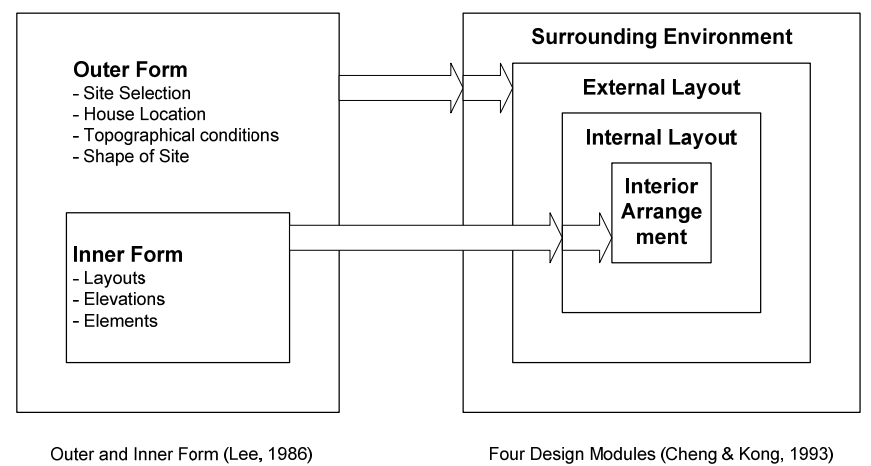

Figure 3 Four Design Modules 
Source: Mak (2004)

\subsection{CONCEPT OF FENG SHUI DESIGN CRITERIA}

Most contemporary Feng Shui scholars (Lip, 1979, 1986; Rossbach, 1984, 1987; Lee, 1986; Xu, 1990; Han, 1995; and Choy, 1999) have set up their own criteria for Feng Shui design. For instance, Lee (1986) outlined threebasic-criteria for architectural design; Xu (1990) derived a four-step landscape model to deal with land formations; Han (1995) used 24-major criteria for selection of the best location; Lip $(1979,1986)$ listed a set of standard rules of thumb for assessment of architectural design; Choy (1999) suggested a ten-point design criteria checklist for property selection; and Rossbach $(1984,1987)$ provided a set of interior design diagrams for furniture placement. Although these criteria derived from various contemporary Feng Shui scholars were presented in different formats, they all follow the principles and practice of the Form School approach.

Based on these contemporary practices for Feng Shui design, 24 key criteria are identified (Mak, 2004) and grouped according to the four design modules as shown in Figure 4.

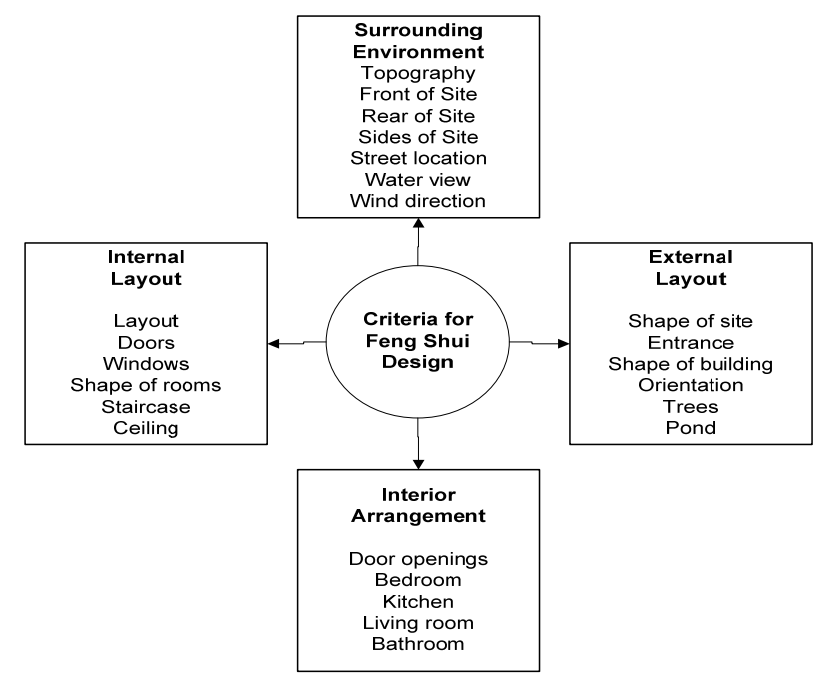

Figure 4 Feng Shui Criteria Grouped in Four Design Modules Source: Mak (2004)

\section{FENG SHUI DESIGN FRAMEWORK}


Based on these four fundamental concepts of the Form School approach, i.e. the concept of the Feng Shui model, the concept of parallelism, the hierarchy of four design modules, and criteria for Feng Shui design, an overall view of the Form School approach was provided. It is necessary to integrate these four fundamental concepts into a single diagrammatical organization of the Form School approach as shown in Figure 5. This diagram indicated that all these four fundamental concepts were integrated and interrelated, and no single concept should be considered in isolation. For instance, the concept of the Feng Shui model integrated with the concept of parallelism that reflected in the hierarchy of four design modules, and the criteria for Feng Shui design corresponding to the concepts of the Feng Shui model that applied to the hierarchy of four design modules.

Based on the organization of the Form School approach, it is necessary to formulate a suitable process to integrate the four fundamental concepts of Feng Shui knowledge. It is recognised that a concept hierarchy approach provides a powerful way to represent structural knowledge (Tam, 1993). Using a concept hierarchy, the relationship between each piece of data can be expressed and presented allowing the data stored in the database with abstract term (Lee et al., 1997). Concept hierarchy is used to organize factual domain knowledge and symbolic structural knowledge in the form of a generalization hierarchy. It is a common approach to utilize concept hierarchy for organizing structural knowledge and constructing the knowledge base because of its efficient mechanism to store and generalize a large body of interrelated concepts (Tam, 1993).

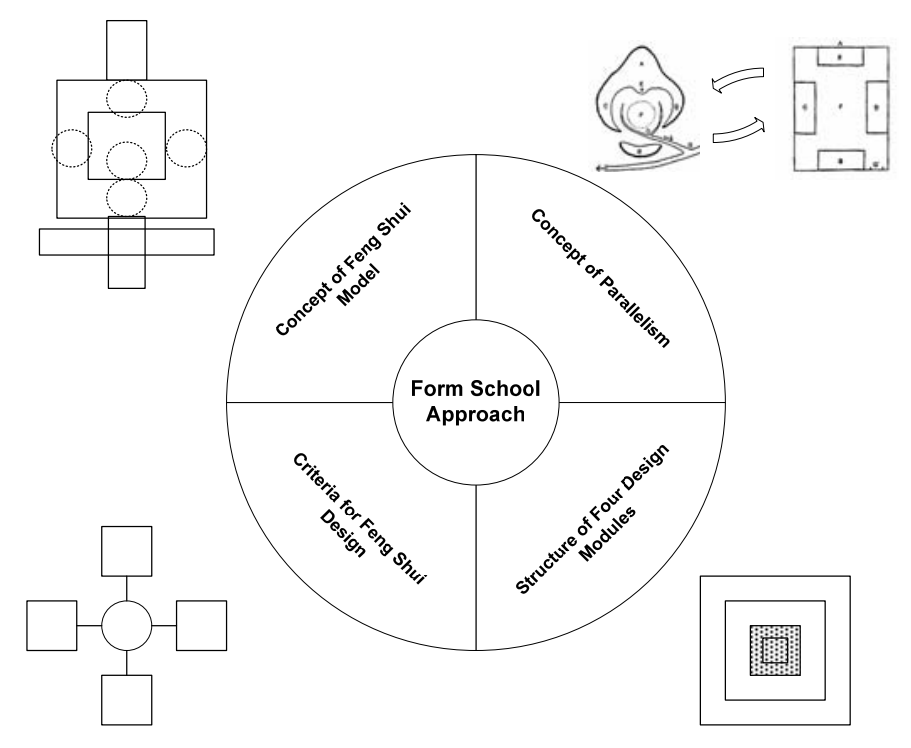


Figure 5 Organization of the Form School Approach

Source: Mak (2004)

When constructing a concept hierarchy of the Feng Shui knowledge, the four fundamental concepts are first represented in a format of hierarchy and are then integrated to form a skeletal structure of the outline hierarchy of the Feng Shui knowledge (see Figure 6).

Although the four fundamental concepts provides a broad understanding of the Form School approach, a hierarchical structure of Feng Shui knowledge has never been established. Here, a conceptual framework for the hierarchical structure of Feng Shui knowledge has been established to provide a detail understanding of the Form School approach and to create a structured framework for building design. This hierarchical structure will be further developed to incorporate specific design conditions related to each of the Feng Shui criterion. The completed hierarchical structure of Feng Shui knowledge will be tested for relevancy and accuracy. 


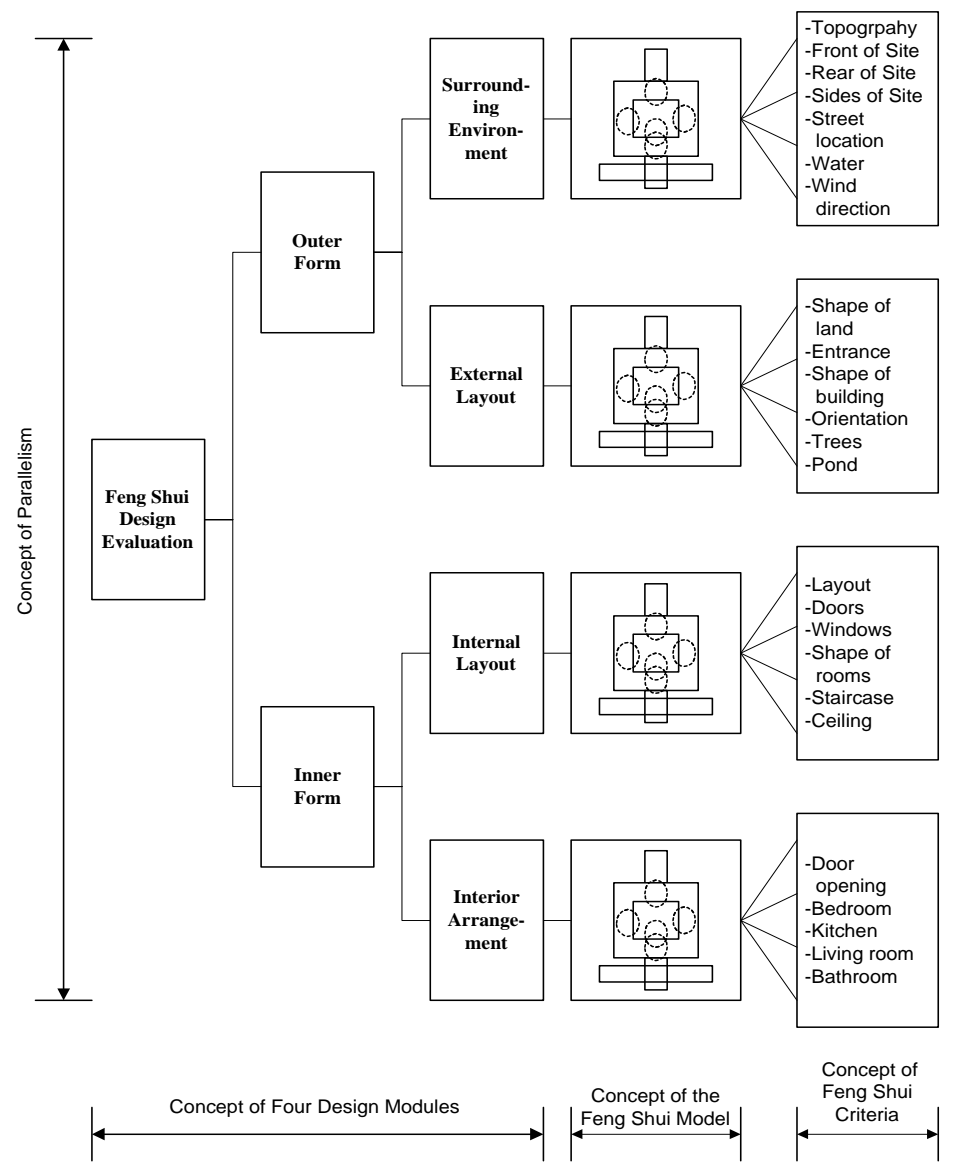

Figure 6 Conceptual Framework of Feng Shui Knowledge Source: Mak et al. (2005)

\section{CONCLUSIONS}

Building design was recognized as a very complex and intuitive process. Architects used their knowledge accumulated from intuition and past experiences to make heuristic design decisions. These characteristics are similar to Chinese philosophy of direct insight into the nature and the principles and practices of Feng Shui as applied in ancient Chinese architecture. It is suggested that interpreting Feng Shui knowledge would enable the development of a design framework from this Chinese architectural discipline. In particular, the Form School provided a holistic approach that allows integrated components and elements to be 
considered for the built environment. Based on the Form School approach, four fundamental concepts were derived and a conceptual framework for Feng Shui design was established.

The purpose of this paper is not to give Feng Shui knowledge validity from a western perspective of science, and it is not set out to challenge conventional theories of architectural design. Rather, this Feng Shui design framework suggests the significance of an unconventional alternative system of analysis in building design.

\section{REFERENCES}

Archer, L.B. (1969) The Structure of the Design Process. IN: Broadbent, G. and Ward, T. (eds) Design Methods in Architecture. London, Lund Humphries, pp.76-102.

Asimow, M. (1962) Introduction to Design. Englewood Cliffs, Prentice Hall. Cheng, Jianjun and Kong, Shangpo (1993) Feng Shui and Architecture. Nanchang, Jiangxi Science and Technology Press [in Chinese].

Chiou, S-C and Krishnamurti, R. (1997) Unraveling Feng Shui. Environment

and Planning B: Planning and Design, Vol. 24, pp.549-572.

Choy, H. (1999) Go with the Flow. IN: Property Council of Australia, Residential Property Investors Guide, p.19.

Feuchtwang, S.D.R. (1974). An Anthropological Analysis of Chinese Geomancy. Vientiane, Laos, Vithagna.

Gregory, S.A. (ed.) (1966) The Design Method. London, Butterworth.

Han, Ke-Tsung (1995) Basic Theory of Landscape Feng Shui. Taipei, Lamper Enterprises [in Chinese].

He, Xiaoxin (1990) The Source of Feng Shui. Nanjing, Southeast University Press [in Chinese].

He, Xiaoxin and Luo, Jun (1995) History of Chinese Feng Shui. Shanghai, Shanghai Arts and Literature Press [in Chinese].

He, Xiaoxin. (1998) Feng Shui: Chinese Tradition in a Manchester Context. PhD Thesis, University of Manchester.

Humphreys, C. (1976) Zen Buddhism. London, Allen \& Unwin.

Hwangbo, A. B. (1999) In Search of Alternative Traditions in Architecture: a Cross-Cultural Interdisciplinary Study. PhD Thesis in Architecture, University of Sheffield.

Jones, J. C. (1970) Design Methods. John Wiley and Sons.

Jones, J.C. (1963) A Method of Systematic Design. IN: Jones, J.C. and Thronley, D. (eds) Conference on Design Methods. Oxfords, Pergamon.

Jung, I. (1996) A knowledge-based approach to computer-aided architectural design and evaluation using cost estimation as an illustration. PhD Thesis, University of Sheffield.

Kuhn, T.S. (1970) The Structure of Scientific Revolutions, Second Edition. Chicago, University of Chicago Press. 
Lee, D.H., Kim, S.W., Methou, G. and Lee, J.Y. (1997) Search for the Blind: A Schema Independent Query Method Using Concept Hierarchy and Keywords. Computers Industry and Engineering, Vol. 33, Nos 3-4, pp.657-660.

Lee, Sang-Hae (1986) Feng Shui: Its Context and Meaning. PhD Thesis, Cornell University.

Lip, E. (1979) Chinese Geomancy. Singapore, Times Books International.

Lip, E. (1986) Feng Shui for the Home. Singapore, Heian International.

Mak, M.Y. (2004) Application of Feng Shui Knowledge to Preliminary Design Evaluation using Knowledge-Based Expert Systems Approach. PhD Thesis, University of Newcastle, Australia.

Mak, M.Y. and Ng, S.T. (2005) The Art and Science of Feng Shui - A Study

on Architects' Perception. Building and Environment, 40, pp.427-434.

Mak, M.Y., Ng, S.T. and Chen, S.E. (2005) Formulating a hierarchical structure of Feng Shui knowledge. IN: Loforte, F. et al. (Ed.) Information and Knowledge Management in a Global Economy. Instituto Superior Técnico, Lisbon, Portugal, pp.395-404.

Poincare, H. (1929) The Foundations of Science. New York, Science House Inc.

Popper, K.R. (1972) Conjectures and Refutations: The growth of scientific knowledge, Fourth Edition. London, Routledge and Kegan Paul.

Raftery, J. (1991). Principles of Building Economics. Blackwell Scientific Publications.

Rossbach, S. (1984) Feng Shui. London, Rider.

Rossbach, S. (1987) Interior Design with Feng Shui. London, Rider.

Sargent, P. (1994) Design Science or Nonscience. Design Studies, Vol. 15, No. 4, pp.389-402.

Shang, Kuo (1992) China's Pattern of Feng Shui: Its Formation, Relationship to Environment and Landscaping. IN: Wang, Qiheng (ed.) Research of Feng Shui Theory. Tianjin, Tianjin University Press, pp.2632 [in Chinese].

Simon, H.A. (1969) The Sciences of the Artificial. Cambridge, The MIT Press.

Skinner, S. (1982) The Living Earth Manual of Feng Shui Chinese Geomancy. London, Arkana.

Suckle, A. (1980) By Their Own Design. New York, Granada.

Tam, K.Y. (1993) Applying Conceptual Clustering to Knowledge-Bases Construction. Decision Support Systems, 10, pp.173-198.

Too, L. (1996) The Complete Illustrated Guide to Feng Shui. London, Element.

Wang, Qiheng (ed.) (1992) Research of Feng Shui Theory. Tianjin, Tianjin University Press [in Chinese]. 
Xu, Ping (1990) Feng Shui: A model for Landscape Analysis. DrDes Thesis, Harvard University.

Yi, Ding, Yu, Lu and Hong, Yong (1996) Geomancy and the Selection of Architecture Placement in Ancient China. Shi Jia Zhuang, Hebei Science and Technology Press [in Chinese]. 